\title{
Experimental Research and Numerical Simulation on Grouting Quality of Shield Tunnel Based on Impact Echo Method
}

\author{
Fei Yao, Guangyu Chen, and Jianhong Su \\ College of Civil and Transportation Engineering, Hohai University, Nanjing, Jiangsu 210098, China \\ Correspondence should be addressed to Fei Yao; yaofei215@sina.com
}

Received 29 June 2016; Revised 19 September 2016; Accepted 16 October 2016

Academic Editor: Sergio De Rosa

Copyright ( 2016 Fei Yao et al. This is an open access article distributed under the Creative Commons Attribution License, which permits unrestricted use, distribution, and reproduction in any medium, provided the original work is properly cited.

\begin{abstract}
To identify shield grouting quality based on impact echo method, an impact echo test of segment-grouting (SG) test piece was carried out to explore effect of acoustic impedance of grouting layers and grouting defects on impact echo law. A finite element numerical simulation on the impact echo process was implemented. Test results and simulation results were compared. Results demonstrated that, under some working conditions, finite element simulation results and test results both agree with theoretical values. The acoustic impedance ratio of SG material influenced the echo characteristics significantly. But thickness frequency could not be detected under some working conditions because the reflected energy is weak. Frequency feature under grouting defects was more complicated than that under no grouting defects.
\end{abstract}

\section{Introduction}

Shield method has advantages such as characteristic security, speediness, wide application range, and small disturbance to surrounding strata. It is widely applied in subway construction engineering in cities. Since the outer diameter of shield is larger than the circumferential outer diameter of segment, a circumferential overexcavation gap will be formed between the segment and surrounding rocks. Together with construction disturbance and blasting excavation, the supporting structure separates from surrounding rocks, thus resulting in relaxation of surrounding rocks. Consequently, the supporting structure will suffer excessive bending stress and its carrying capacity will be reduced, which threatens safe use of the tunnel. In the engineering, the backfill grouting is filled, which can fill the above-mentioned overexcavation gap in Figure 1 but also can prevent relaxation of surrounding rocks and segment leakage as well as reducing surface subsidence significantly.

However, when there is problem in grouting density and even development of holes, cross section of the tunnel will change and will affect traffic safety directly when such change becomes serious. Surface subsidence or stress changes of surrounding soil mass will be produced upon great surrounding rock strain, thus causing distortion of local soil mass and increasing segment load in the tunnel indirectly. This makes engineering practices disagree with design and investigation, which increases risks significantly. At present, shield grouting quality is mainly detected by radar method $[1,2]$. However, radar method is expensive and easy to be disturbed by metallic shield. Therefore, exploring a new detection approach of grouting quality of shield segment becomes an urgent and hot new field.

Impact echo method [3-6] is a structural nondestructive testing technology based on transient stress wave. It impacts the concrete surface by a steel ball or hammer as an exciter to produce longitudinal wave ( $\mathrm{P}$ wave) and transverse wave ( $\mathrm{S}$ wave) in the concrete structure as well as Rayleigh wave ( $R$ wave) on the concrete surface [7, 8]. Stress waves will form echoes through propagation and reflections in concrete [9, 10]. Surface displacement caused by reflection of these waves will be recorded by a sensor close to the impact position. After receiving these waves, the sensor will transform signals in time domain into the frequency domain through Fast Fourier Transform (FFT) and recognize the relationship between the received signal and concrete mass, thus realizing the goal of nondestructive test.

Impact echo method has been used successfully in many engineering fields, such as girder test of bridges, pipeline inwall integrity test, bridge surface damage test, and highway 
TABLE 1: Material parameters of SG samples.

\begin{tabular}{lcccc}
\hline Group & $\begin{array}{c}\text { Grouting elasticity } \\
\text { modulus/ } E_{G} \\
(\mathrm{MPa})\end{array}$ & $\begin{array}{c}\text { Grouting density/ } \rho_{G} \\
\left(\mathrm{~kg} / \mathrm{m}^{3}\right)\end{array}$ & $\begin{array}{c}\text { Segment elasticity } \\
\text { modulus } / E_{S} \\
(\mathrm{MPa})\end{array}$ & $\begin{array}{c}\text { Segment density/ } \rho_{S} \\
\left(\mathrm{~kg} / \mathrm{m}^{3}\right)\end{array}$ \\
\hline SG-A & 2350 & 1539 & 34500 & 2500 \\
SG-B & 6900 & 1913 & 34500 & 2500 \\
SG-C & 11330 & 1947 & 34500 & 2500 \\
\hline
\end{tabular}

TABLE 2: Acoustic parameters of SG samples.

\begin{tabular}{|c|c|c|c|c|c|}
\hline Group & $\begin{array}{l}\text { Segment wave velocity } \\
\left(C_{p 1}\right) \\
(\mathrm{m} / \mathrm{s})\end{array}$ & $\begin{array}{c}\text { Segment acoustic } \\
\text { impedance }\left(Z_{1}\right) \\
\left(\mathrm{kg} / \mathrm{m}^{2} \mathrm{~s}\right)\end{array}$ & $\begin{array}{l}\text { Grouting wave velocity } \\
\qquad \begin{array}{c}\left(C_{p 2}\right) \\
(\mathrm{m} / \mathrm{s})\end{array}\end{array}$ & $\begin{array}{c}\text { Grouting acoustic } \\
\text { impedance }\left(Z_{2}\right) \\
\left(\mathrm{kg} / \mathrm{m}^{2} \mathrm{~s}\right)\end{array}$ & Reflectance $(R)$ \\
\hline SG-A & 4390 & $10.98 \times 10^{6}$ & 1354 & $2.08 \times 10^{6}$ & -0.68 \\
\hline SG-B & 4390 & $10.98 \times 10^{6}$ & 2081 & $3.98 \times 10^{6}$ & -0.47 \\
\hline SG-C & 4390 & $10.98 \times 10^{6}$ & 2643 & $5.22 \times 10^{6}$ & -0.36 \\
\hline
\end{tabular}

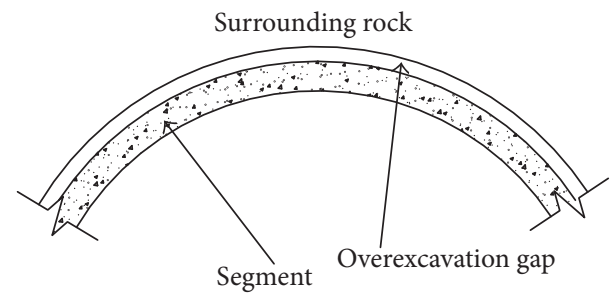

FIGURE 1: Overexcavation gap caused in shield construction.

pavement quality test $[4,11,12]$. However, there are few researches on shield grouting quality test. In shield tunnel, grouting defects belong to concealed defects and a layered structure will be formed by segment and grouting layer. With respect to the testing structure composed of layered materials, acoustic impedances of different layers of materials will affect the impact echo test results significantly. On this basis, this paper performed impact echo tests to SG samples with different acoustic impedances to discuss effect of acoustic impedance ratio and grouting defect on impact echo law. A finite element numerical simulation on the impact echo process was accomplished by using the finite element software MSC.MARC [13]. Test results and simulation results were compared.

\section{Experimental Study}

2.1. Experiment Design. To study the effect of acoustic impedance of the grouting layer, three segment-grouting (SG) samples with different proportions of grouting layers were designed: SG-A, SG-B, and SG-C. Specific materials parameters are listed in Table 1 . The three-shield capping segments made by Nanjing Ligao Segment Co., Ltd., were used. The compressive strength was $50 \mathrm{Mpa}$ and the size was $1200 \mathrm{~mm} \times 1200 \mathrm{~mm} \times 350 \mathrm{~mm}$ (Figure 2). Thickness of the grouting layer was $100 \mathrm{~mm}$ (Figure 3).

Poisson's ratios of the grouting layer and segment layer were approximately determined, 0.25 and 0.3 , respectively [14]. Wave velocity, $C_{P}$, acoustic impedance, $Z$, and reflectance of different layers of materials, $R$, were calculated by the following formula and represented in Table 2.

$$
C_{P}=\sqrt{\frac{E(1-\mu)}{\rho(1+\mu)(1-2 \mu)}},
$$

where $E$ is the elasticity modulus; $G$ is the shear modulus; $\rho$ is the density of medium; $\mu$ is the Poisson's ratio.

$$
Z=\rho \times C_{P},
$$

where $Z$ is the acoustic impedance of medium.

$$
R=\frac{A_{\text {Reflected }}}{A_{\text {Incident }}}=\frac{Z_{2}-Z_{1}}{Z_{2}+Z_{1}}
$$

where $Z_{1}$ and $Z_{2}$ are the acoustics impedance of medium 1 and medium 2; $A_{\text {Incident }}$ is amplitude of the incident wave; $A_{\text {Reflected }}$ is amplitude of the reflected wave.

To study effect of defects, a piece of foam board was embedded into the left half of three SG samples, which were compared with the SG sample without defect (the right half). To ensure that the embedded foam board could be detected [7], width of the foam board was set to be $150 \mathrm{~mm}$. Thickness of the foam board was $20 \mathrm{~mm}$ and it was embedded at $30 \mathrm{~mm}$ away from the segment-grouting interface (Figure 3). The segment was simply supported at four corners. Therefore, SGA samples were further divided into SG-A-DE (with defect) and SG-A-ND (without defect). Similarly, SG-B samples were divided into SG-B-DE and SG-B-ND, and SG-C samples were further divided into SG-C-DE and SG-C-ND.

2.2. Experimented Setup. The IES (Impact Echo Scanning) instrument which is manufactured by Olson Instrument Company was used in this test (Figure 4). The instrument includes the host computer, cable, and a scrolling sensor which contain signal receiving sensor and can adjust the exciter to different excitation intensity.

The sampling frequency is set as $2048 \mathrm{~Hz}$, which indicates that data points collected every 10 microseconds, and order is set as 4 th order. 


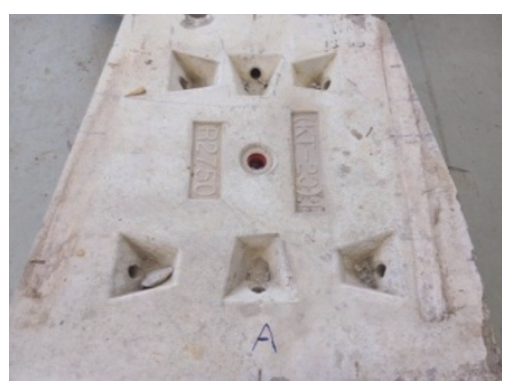

(a) Segment-A

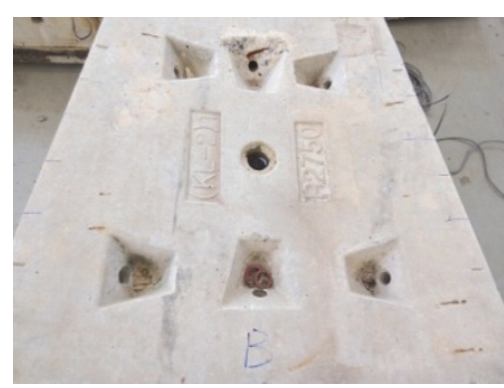

(b) Segment-B

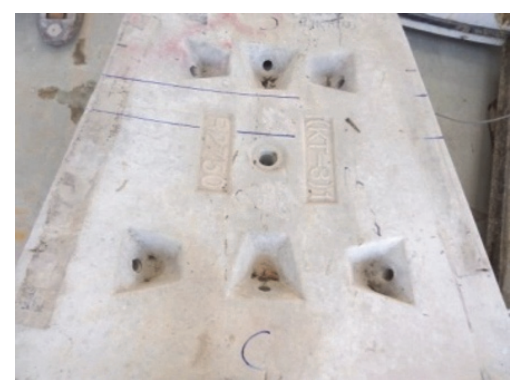

(c) Segment-C

FIGURE 2: Concrete segments.
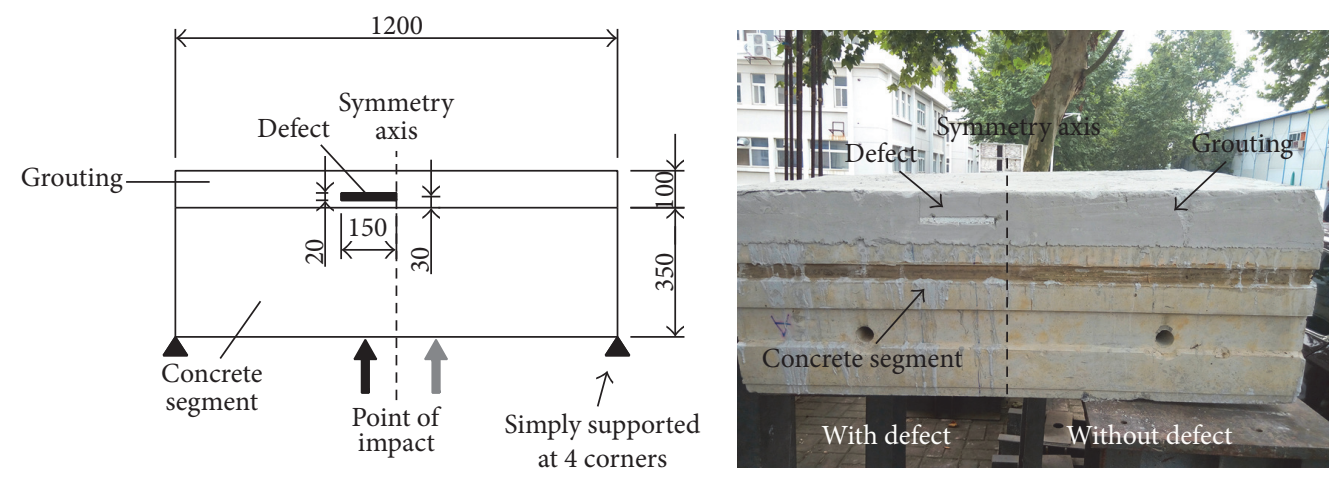

FIGURE 3: Structure of SG samples.

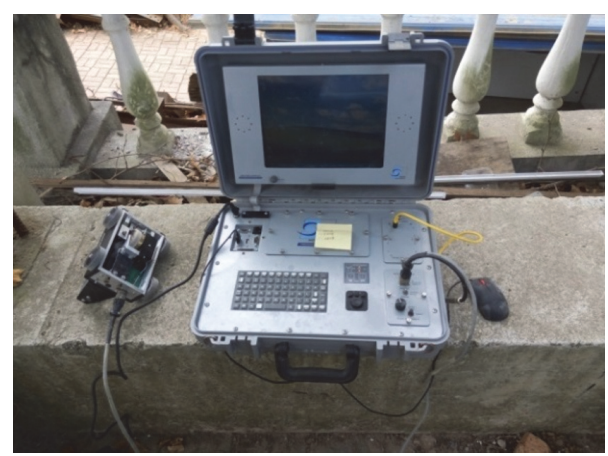

FIGURE 4: IES (Impact Echo Scanning) instrument.

2.3. Theoretical Calculation. The test principle of impact echo method is based on the relationship between the test frequency and stress wave velocity as well as sample thickness [15-17]:

$$
f_{T}=\frac{\beta C_{P}}{2 T},
$$

where $f_{T}$ is the peak frequency gained after FFT of timehistory curve that is collected by the sensor; $\beta$ is the shape factor and is determined as 1 in this paper [18]; $C_{P}$ is stress wave velocity in this medium; and $T$ is thickness of the sample.

When a component is composed of two different materials [19], the thickness frequency from the bottom surface to the top surface is

$$
f_{h}=\frac{1}{2 h_{1} / \beta C_{p 1}+2 h_{2} / \beta C_{p 2}},
$$

where $h_{1}$ and $h_{2}$ are thicknesses of material 1 and material 2; $C_{p 1}$ and $C_{p 2}$ are stress wave velocities in material 1 and material 2.

According to above theories, thickness frequency $f_{1}$ of the segment-grouting interface could be calculated from

$$
f_{1}=\frac{\beta C_{p 1}}{2 T_{1}} .
$$

Thickness frequency $f_{2}$ of the grouting-air interface is

$$
f_{2}=\frac{1}{2 T_{1} / \beta C_{p 1}+2 T_{2} / \beta C_{p 2}},
$$

where $T_{1}$ and $T_{2}$ are thicknesses of concrete segment and grouting; $C_{p 1}$ and $C_{p 2}$ are stress wave velocities in concrete segment and grouting.

Similarly, thickness frequency $f_{2}^{\prime}$ at the defect could be calculated from

$$
f_{2}^{\prime}=\frac{1}{2 T_{1}^{\prime} / \beta C_{p 1}+2 T_{2}^{\prime} / \beta C_{p 2}},
$$

where $T_{1}^{\prime}$ and $T_{2}^{\prime}$ are thickness of the concrete segment and thickness from segment-grouting interface to defect surface; $C_{p 1}^{\prime}$ and $C_{p 2}^{\prime}$ are stress wave velocities in concrete segment and grouting, respectively.

Theoretical peak frequencies at different interfaces of all samples are listed in Table 3. 
TABLE 3: Theoretical peak frequencies.

\begin{tabular}{lccc}
\hline Specimen number & $f_{1}(\mathrm{~Hz})$ & $f_{2}^{\prime}(\mathrm{Hz})$ & $f_{2}(\mathrm{~Hz})$ \\
\hline SG-A-DE & 6271 & 4908 & 3256 \\
SG-A-ND & 6271 & - & 3256 \\
SG-B-DE & 6271 & 5311 & 3413 \\
SG-B-ND & 6271 & - & 3413 \\
SG-C-DE & 6271 & 5489 & 4253 \\
SG-C-ND & 6271 & - & 4253 \\
\hline
\end{tabular}

TABLE 4: Comparison between tested peak frequency and theoretical results under different working conditions.

\begin{tabular}{lccc}
\hline Model number & $f_{1}(\mathrm{~Hz})$ & $f_{2}^{\prime}(\mathrm{Hz})$ & $f_{2}(\mathrm{~Hz})$ \\
\hline SG-A-DE & $6738(6271)$ & $4590(4908)$ & Not obvious (3256) \\
SG-A-ND & $6348(6271)$ & - & $3027(3256)$ \\
SG-B-DE & $6543(6271)$ & $4883(5311)$ & Not obvious (3413) \\
SG-B-ND & $6640(6271)$ & - & $3516(3413)$ \\
SG-C-DE & $6641(6271)$ & $5566(5489)$ & Not obvious $(4253)$ \\
SG-C-ND & $6641(6271)$ & - & $4499(4253)$ \\
\hline
\end{tabular}

Note: values in () are theoretical results.

2.4. Test Results. There is an evident peak value in the effective coverage of thickness frequency $(2000 \sim 8000 \mathrm{~Hz})$ in time domain graph collected from the experiment. Peaks may occur in low-frequency regions beyond the effective coverage, which are caused by surface wave or other noise interference waves. Therefore, a high-pass filtering that took about $2 \mathrm{kHz}$ as the cut-off frequency was implemented to eliminate these strong low-frequency signals [9]. The filtered time domain graph of SG-A-ND is shown in Figure 5.

Frequency domain graphs which were collected after FFT of time-history curves are presented in Figure 6. Filtering of frequencies below $2 \mathrm{kHz}$ is evident in these figures.

Peak frequencies picked from Figure 6 were compared to the theoretical values in Table 4.

It can be seen from Figure 6 and Table 4 that,

(1) in all samples, $f_{1}$ is evident. In samples without defect, $f_{2}$ can be detected, but the peak is smaller than that of $f_{1}$. In samples with defects, $f_{2}$ could not be detected, but $f_{2}^{\prime}$ could and its peak is also smaller than $f_{1}$. All tested peak frequencies are close to theoretical values;

(2) with the increase of grouting acoustic impedance, the absolute value of reflectance of grouting-segment interface decreases gradually and the amplitude of $f_{1}$ decreases gradually as evident from Figure 6. This indicates that, with the reduction of absolute values of the reflectance, the reflected energy of stress wave by this interface declines gradually and the reflectivity weakens. Hence, more energy will be transmitted to the next layer of materials (grouting layer).

\section{Numerical Studies}

3.1. Establishment of SG Finite Element Model. The finite element mode used plane analysis method and number 11

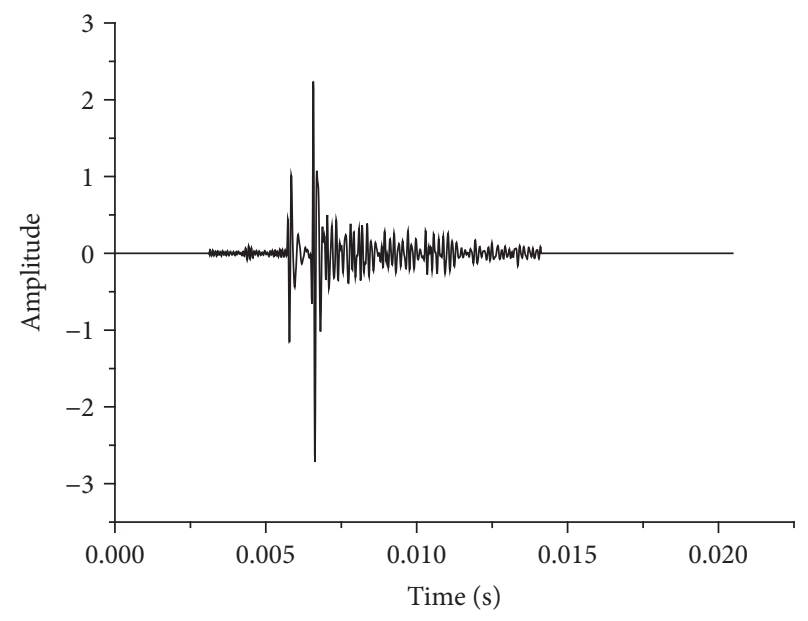

Figure 5: Filtered time domain of SG-A-ND.

two-dimensional plane integrated cells [20]. The impact point was taken as the origin and the excitation directional line was taken as the symmetry axis. A symmetry model was established which was composed of segment and grouting from top to down. The thickness and semiwidth of segment were $350 \mathrm{~mm}$ and $600 \mathrm{~mm}$, while thickness of the grouting was $100 \mathrm{~mm}$ as shown in Figures 2(a) and 2(b). Samples were divided into SG-A-ND (no defect) and SG-A-DE (defect). The defect in SG-A-DE model was a hole whose semilength was $75 \mathrm{~mm}$ and thickness was $20 \mathrm{~mm}$. The upper edge of the hole was $30 \mathrm{~mm}$ below the segment-grouting interface. Parameters of the model materials were same with samples (Figure 7).

The maximum exciting force and excitation time were set as $8 \mathrm{~N}$ and $40 \mu \mathrm{s}$ [21], respectively. Excitation simulation was achieved by applying a concentrated load at the axis of symmetry by using the TABLE function in MSC.MARC as depicted in Figure 8.

3.2. Analysis of Numerical Simulation Results. Velocity-time curve and accelerated-time curve at the node which is $40 \mathrm{~mm}$ away from the impact point were chosen. Figure 9 shows the normalized acceleration-time curve of SG-A with surface waves, while Figure 10 is normalized accelerated-time curves of SG-A with surface waves eliminated.

Through FFT of acceleration-time curves of SG-A without Rayleigh wave, frequency domain graphs under different working conditions were obtained and are shown in Figure 11.

The finite element simulation results and theoretical results were compared in Table 5. The following can be seen from Figure 11 and Table 5:

(1) $f_{1}$ of all samples is evident. Peaks of $f_{2}$ and $f_{2}^{\prime}$ are smaller than that of $f_{1}$. The tested peak frequency is close to the theoretical value.

(2) With the increase of grouting acoustic impedance, the absolute value of reflectance of the groutingsegment interface declines gradually and amplitude of $f_{1}$ decreases gradually, while the amplitude of $f_{2}$ increases. This reflects that the energy reflected by 


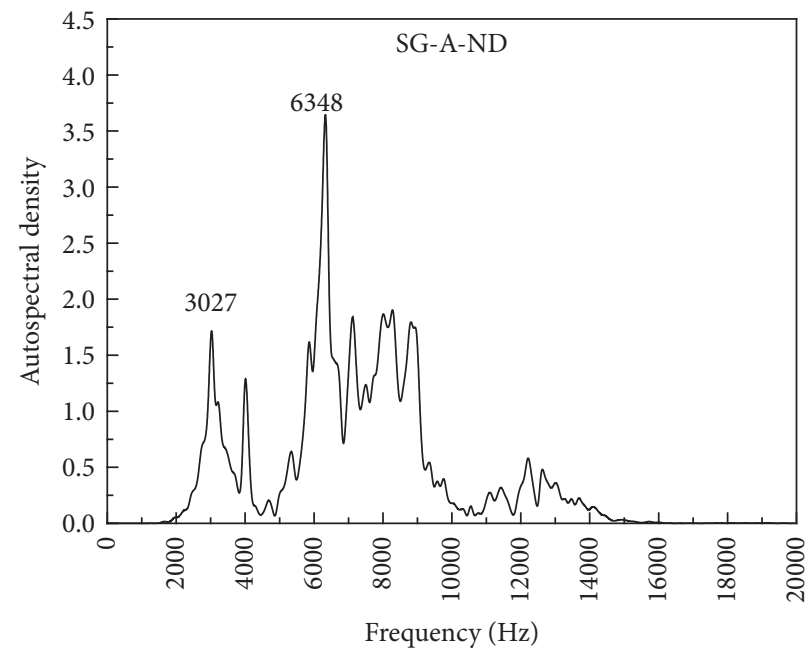

(a) SG-A-ND frequency domain

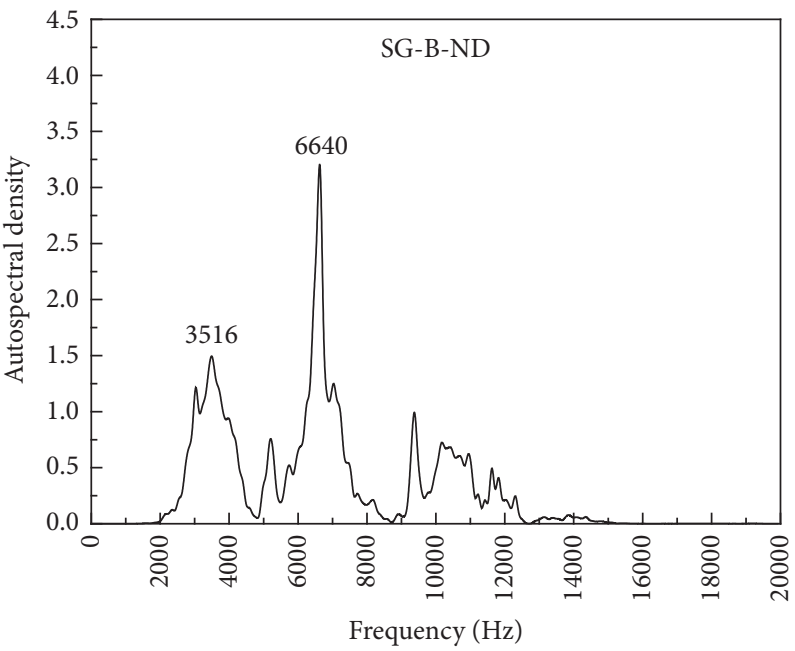

(c) SG-B-ND frequency domain

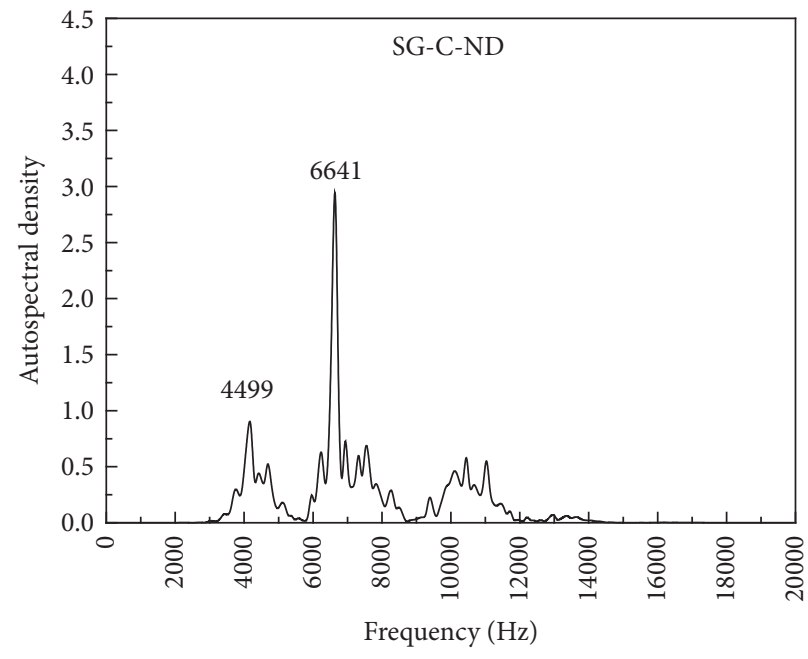

(e) SG-C-ND frequency domain

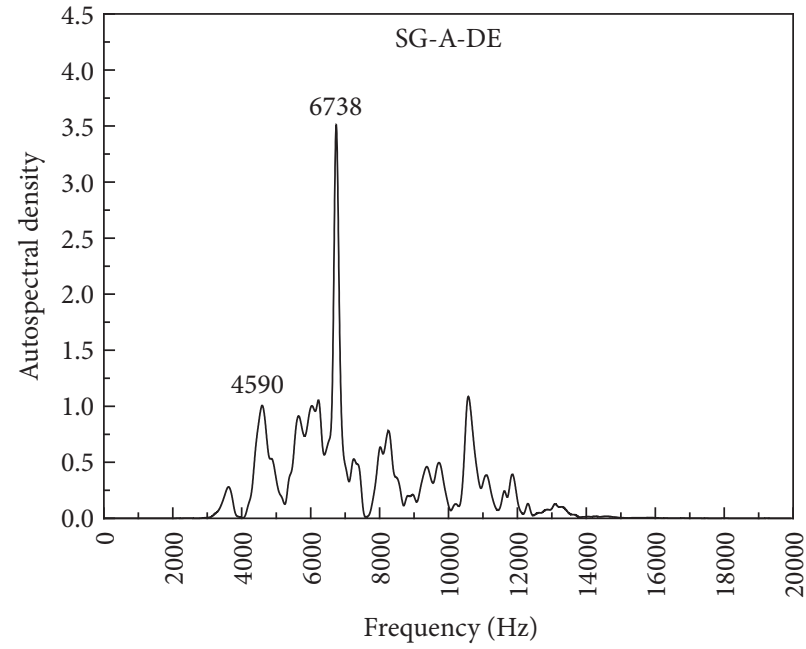

(b) SG-A-DE frequency domain

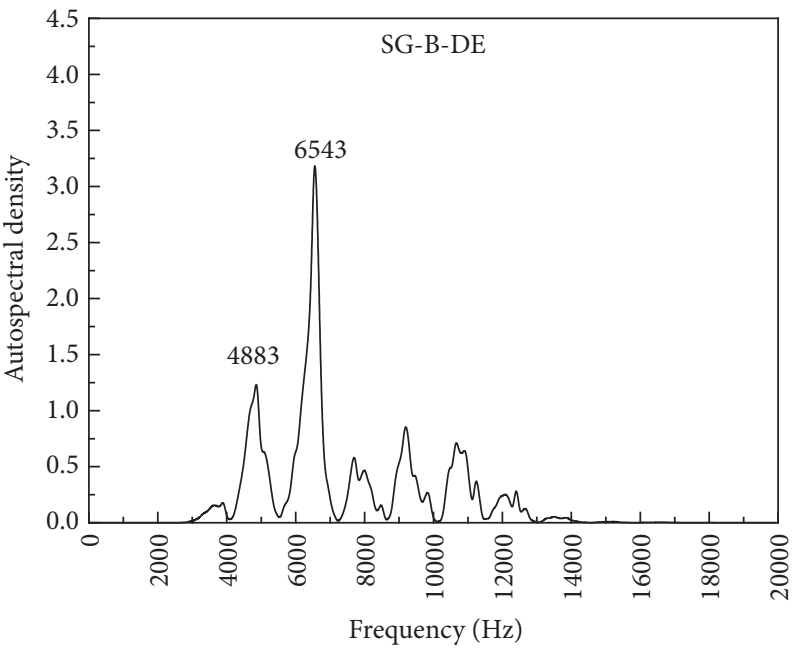

(d) SG-B-DE frequency domain

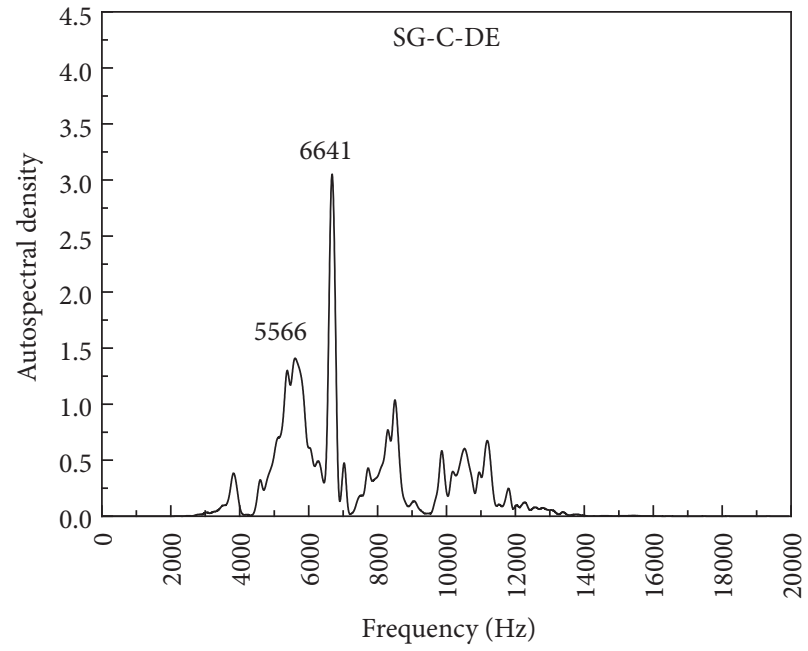

(f) SG-C-DE frequency domain

FIGURE 6: Frequency domain graphs. 


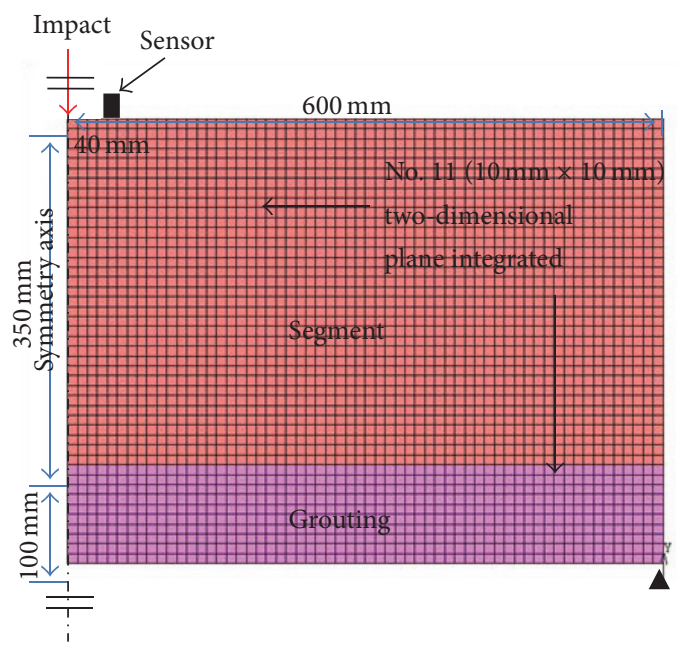

(a) Without defect SG-A-ND



(b) With defect SG-A-DE

FIGURE 7: SG finite element models.

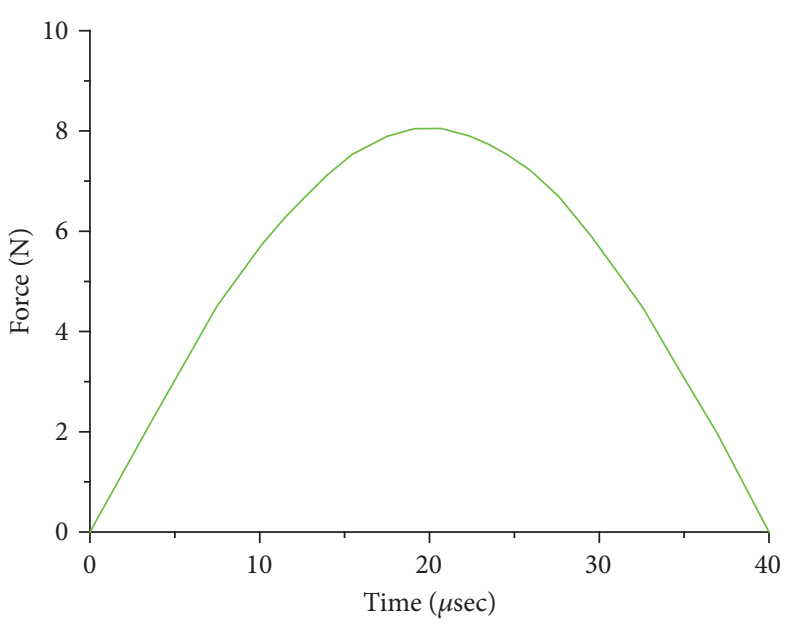

(a) Time-history curve

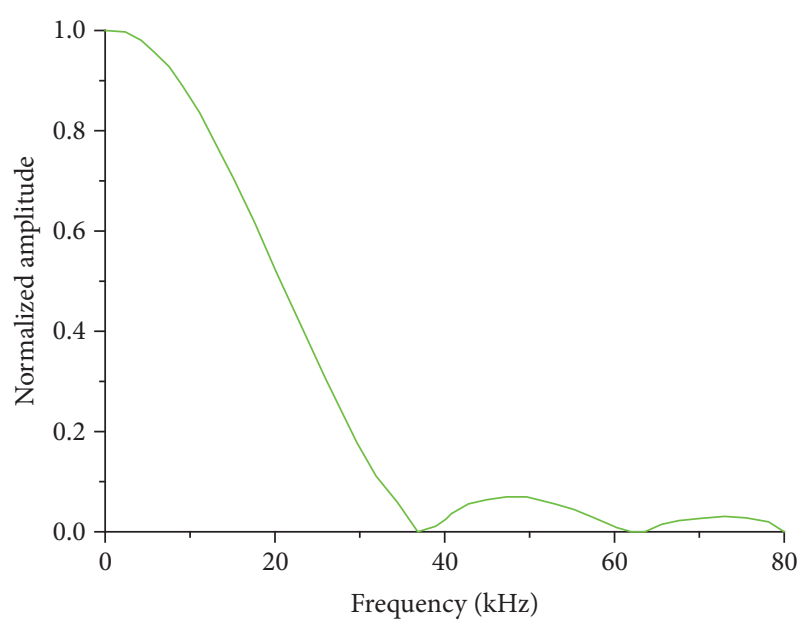

(b) Frequency

FIgURE 8: Simulation parameters of exciting force.
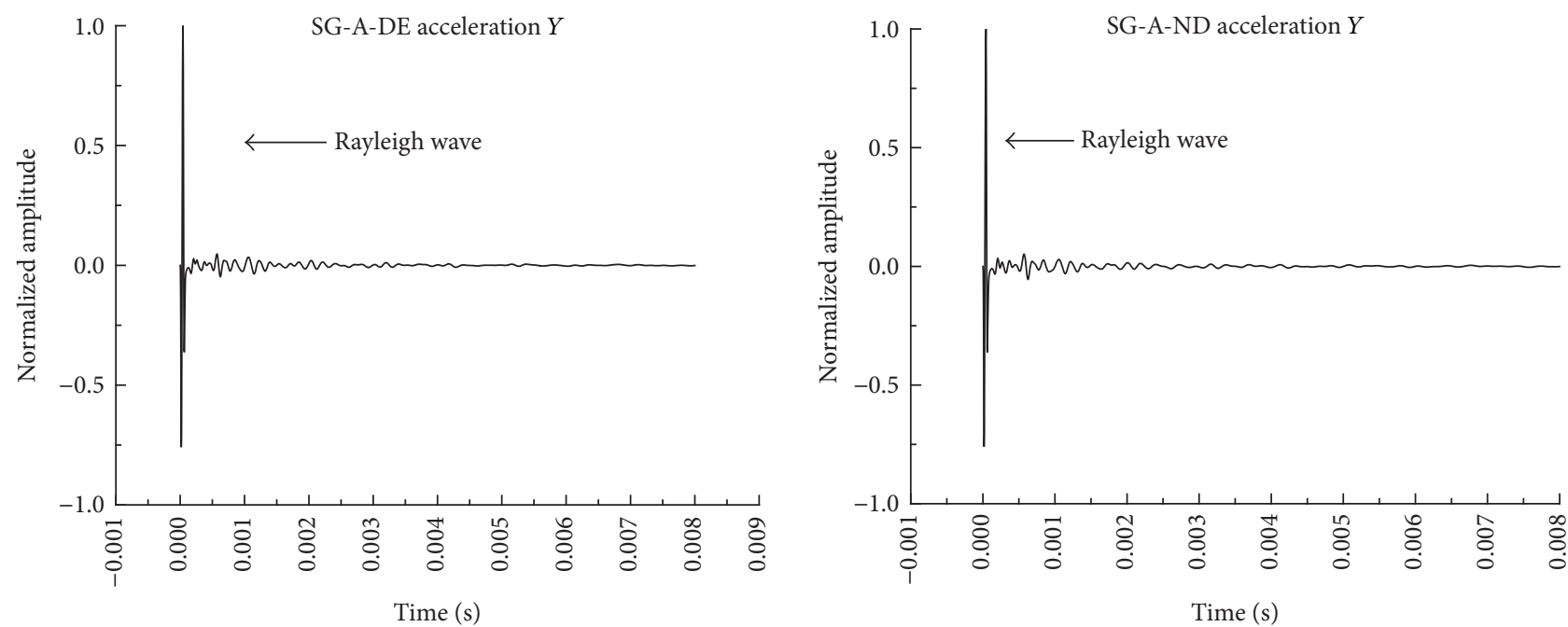

FIgURE 9: Acceleration-time curves of SG-A with surface waves. 

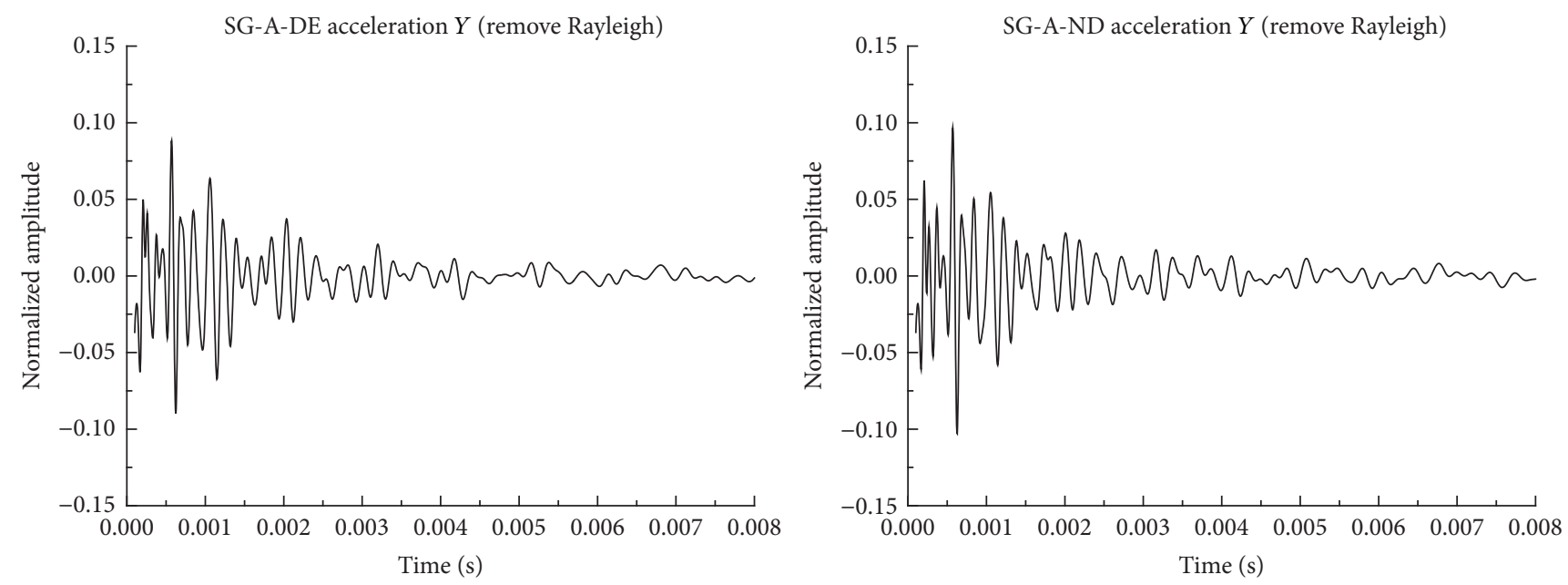

FIGURE 10: Acceleration-time curves of SG-A without surface waves.

TABLE 5: Comparison of peak frequency between finite element simulation and theoretical calculation.

\begin{tabular}{lccc}
\hline Model number & $f_{1}(\mathrm{~Hz})$ & $f_{2}^{\prime}(\mathrm{Hz})$ & $f_{2}(\mathrm{~Hz})$ \\
\hline SG-A-DE & $6104(6271)-\mathbf{2 . 7} \%$ & $5127(4908) \mathbf{4 . 5} \%$ & Not obvious $(3256)$ \\
SG-A-ND & $6104(6271)-\mathbf{2 . 7} \%$ & - & $2930(3256)-\mathbf{1 0 . 0} \%$ \\
SG-B-DE & $6104(6271)-\mathbf{2 . 7} \%$ & $4639(5311)-\mathbf{1 2 . 7} \%$ & $3418(3413) \mathbf{0 . 1} \%$ \\
SG-B-ND & $6348(6271) \mathbf{2 . 1} \%$ & - & $3662(3413) \mathbf{7 . 3} \%$ \\
SG-C-DE & $6348(6271) \mathbf{2 . 1} \%$ & $4883(5489)-\mathbf{1 1 . 0} \%$ & $3662(4253)-\mathbf{1 3 . 9} \%$ \\
SG-C-ND & $6104(6271)-\mathbf{2 . 7} \%$ & - & $4639(4253)-\mathbf{1 3 . 9} \%$ \\
\hline
\end{tabular}

Note: content in ( ) is theoretical results; content in bold is percentage difference between finite element simulated results and theoretical results.

grouting-segment interface is negatively correlated with acoustic impedance ratio. With the increase of acoustic impedance ratio, more and more energies will be transmitted to grouting and reflected on the grouting-air interface.

(3) Same group of SG model showed different frequency features after being given the same stress excitation under conditions with and without defects. SG model with defect presented more complicated frequency features than SG model without defect. Except for SGA-DE which has not obvious $f_{2}$, SG-B-DE and SG-C$\mathrm{DE}$ achieved smaller $f_{2}$ and produced "low-frequency drifts."

Comparison between test results and finite element simulation results is shown in Table 6.

Additionally, viewed from amplitude and variation law of $f_{2}$, the experiment detected fewer wave energies entering into the grouting layer than the finite element simulation and fewer energies reflecting at the defect and the grouting-air interface. This may be because the grouting and segment have not been bonded completely during grouting construction, thus resulting in the difference between stress wave transmission and the ideal state.

Theoretical values, test values, and finite element simulation values of thickness frequency of segment-grouting interface $\left(f_{1}\right)$, thickness frequency at defect $\left(f_{2}^{\prime}\right)$, and thickness frequency of the grouting-air interface $\left(f_{2}\right)$ of different samples are expressed in broken line graphs in Figures 12 and 13.

It can be seen that $f_{2}$ (tested) are not obvious in defective specimens. So if the second peak frequency and the theoretical value of $f_{2}$ vary widely, there may be defects.

\section{Conclusions}

(1) With respect to peak frequencies $f_{1}, f_{2}$, and $f_{2}^{\prime}$, theoretical values, finite element simulation values, and test values are in high accordance under different working conditions, which proves that the impact echo method is feasible to test grouting defect in shield tunnel.

(2) The acoustic impedance ratio between grouting and segment determines reflectance of grouting-segment interface and influences the echo characteristics significantly. In this paper, higher acoustic impedance ratio leads to smaller absolute value of reflectance and smaller echo energy on the segment-grouting interface. Consequently, peak frequency on the frequency graph after FFT is more unobvious, and thickness frequency could not be detected under some working conditions.

(3) Same group of SG model shows different frequency features after being given the same stress excitation under conditions with and without defects. SG model 

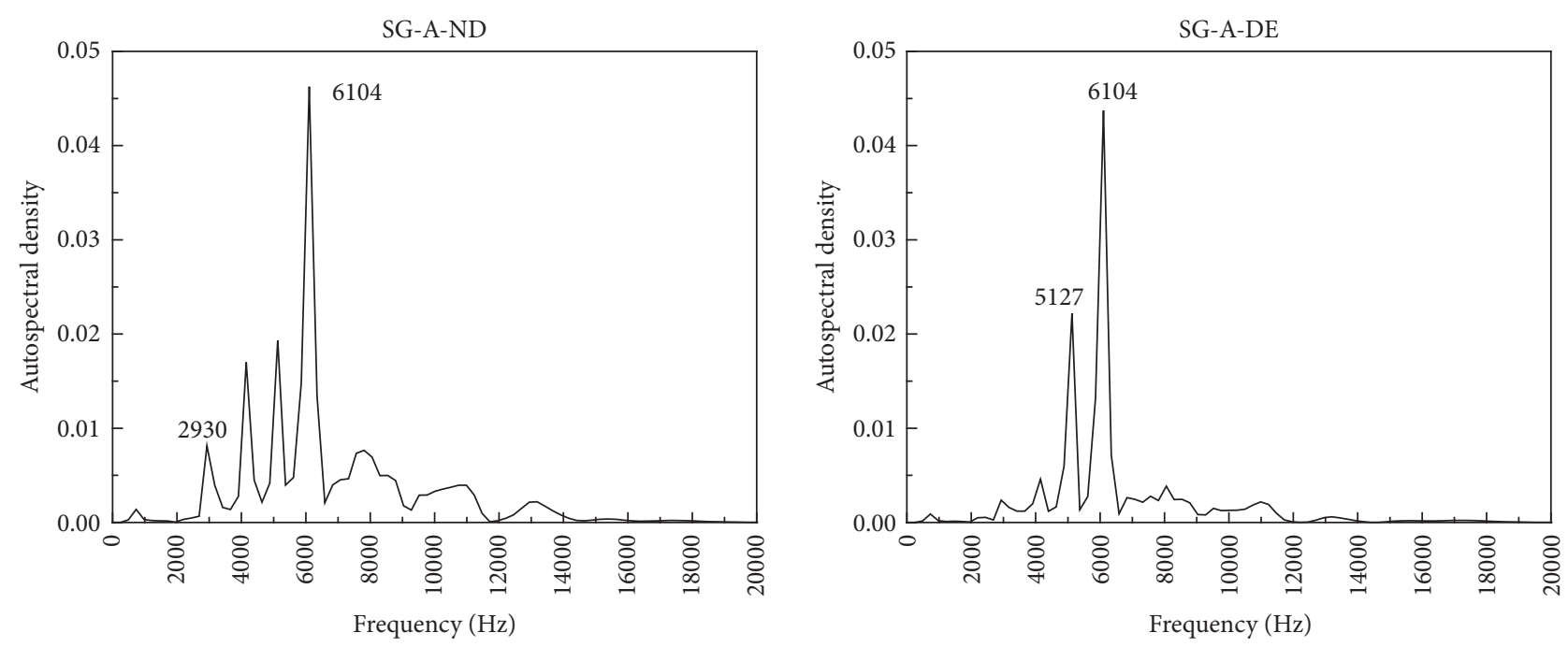

(a) SG-A
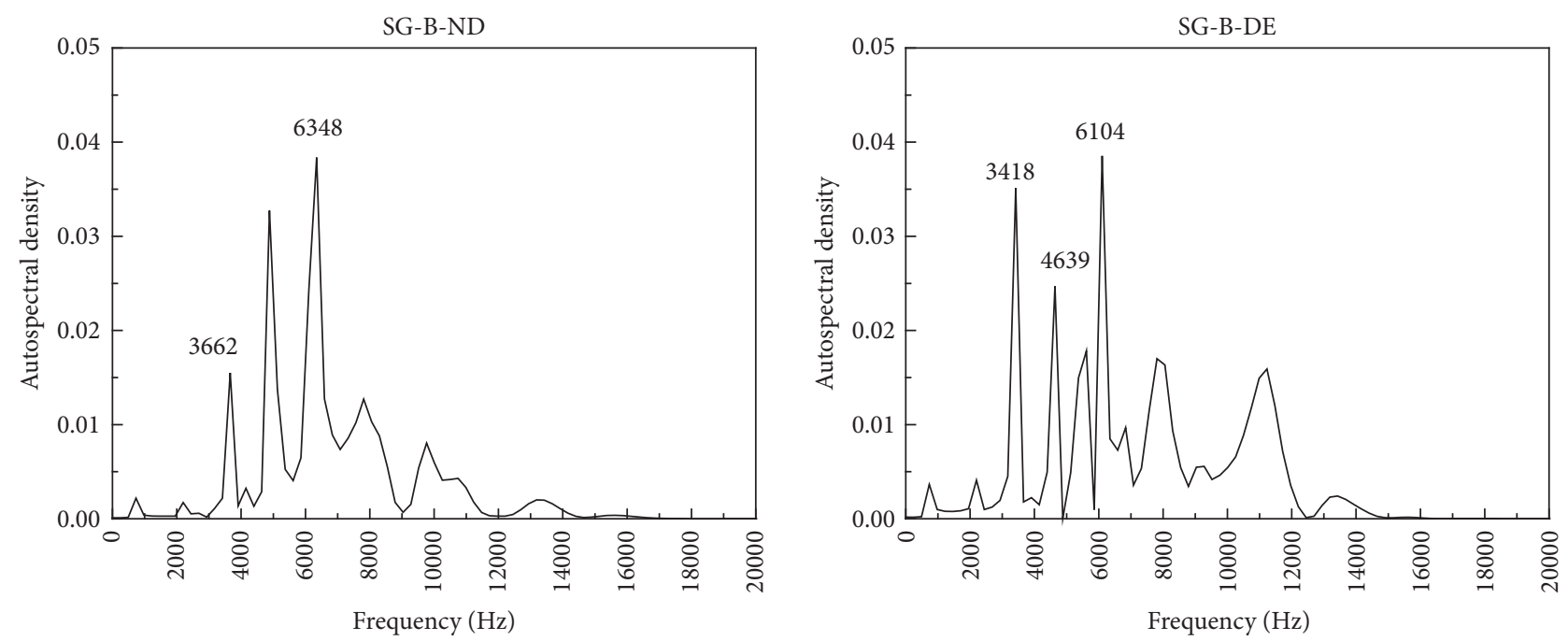

(b) SG-B
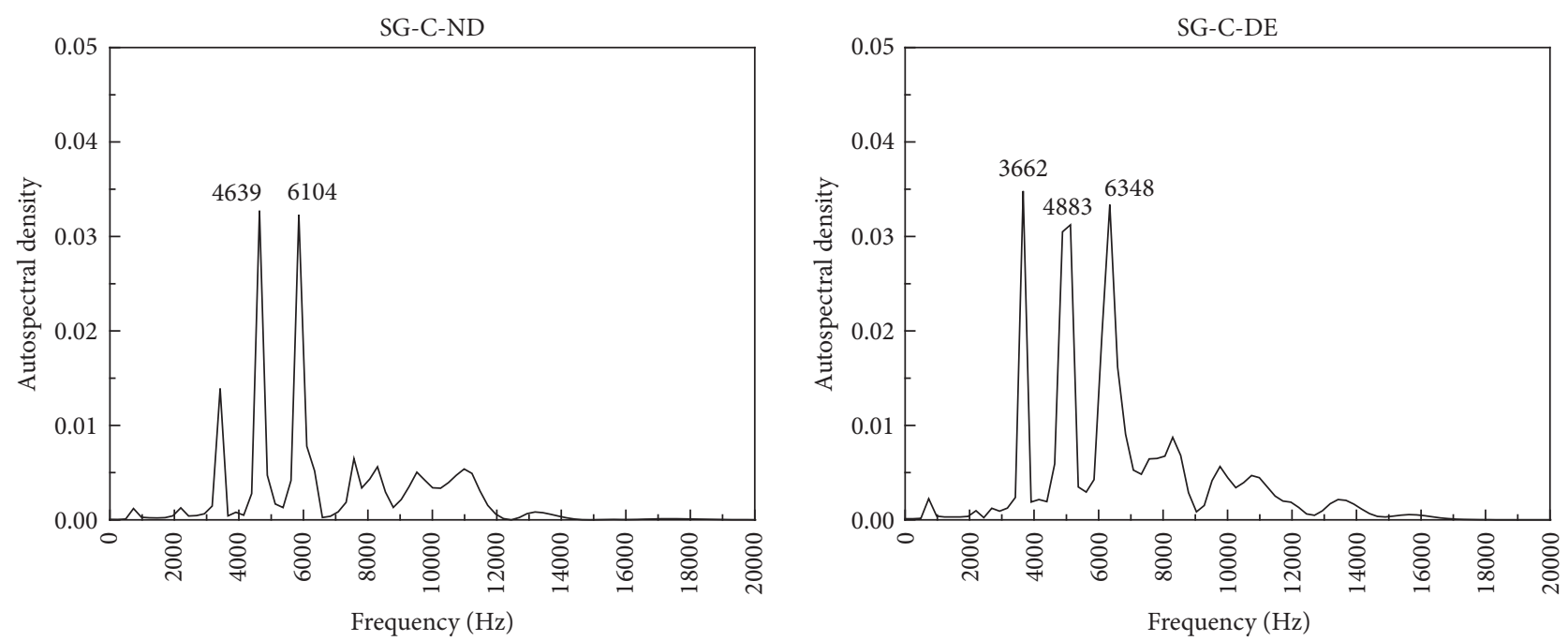

(c) SG-C

FIGURE 11: Frequency domain graphs after FFT of accelerated velocity-time curves. 
TABLE 6: Comparison of peak frequency between test results and finite element simulation under different working conditions.

\begin{tabular}{lccc}
\hline Model number & $f_{1}(\mathrm{~Hz})$ & $f_{2}^{\prime}(\mathrm{Hz})$ & $f_{2}(\mathrm{~Hz})$ \\
\hline SG-A-DE & $6738[6104] \mathbf{1 0 . 4} \%$ & $4590[5127]-\mathbf{1 0 . 5} \%$ & Not obvious [not obvious] \\
SG-A-ND & $6348[6104] \mathbf{4 . 0} \%$ & - & $3042[2930] \mathbf{3 . 8} \%$ \\
SG-B-DE & $6543[6104] \mathbf{7 . 2} \%$ & $4883[4639] \mathbf{5 . 3} \%$ & Not obvious [3418] \\
SG-B-ND & $6640[6348] \mathbf{4 . 6} \%$ & - & $3571[3662]-\mathbf{2 . 5} \%$ \\
SG-C-DE & $6641[6348] \mathbf{4 . 6} \%$ & $5566[4883] \mathbf{1 3 . 9} \%$ & Not obvious [3662] \\
SG-C-ND & $6641[6104] \mathbf{8 . 8} \%$ & - & $4199[4639]-\mathbf{9 . 5} \%$ \\
\hline
\end{tabular}

Note: content in [ ] is finite element simulation results; content in bold is percentage difference between tested results and finite element simulated results.

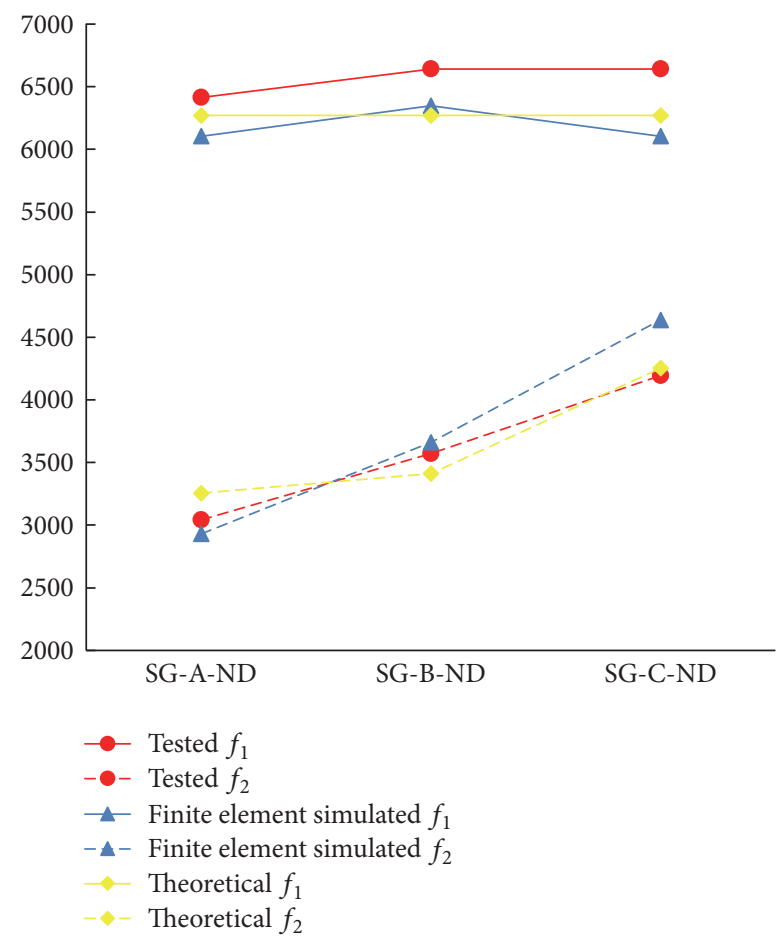

FIGURE 12: Comparison of theoretical values, test values, and finite element simulation values of peak frequency of samples (without defect).

with defect has more complicated frequency features than that without defect due to the existence of three reflective interfaces.

(4) Because of the poor bonding strength between the segment and the grouting during sample preparation, test results disagree with finite element simulation results (ideal conditions). Wave energy transmission in the experiment was more complicated.

\section{Competing Interests}

The authors declare that they have no competing interests.

\section{Acknowledgments}

The present research is financially supported by the Natural Science Foundation of China (Grant no. 51408188) and the

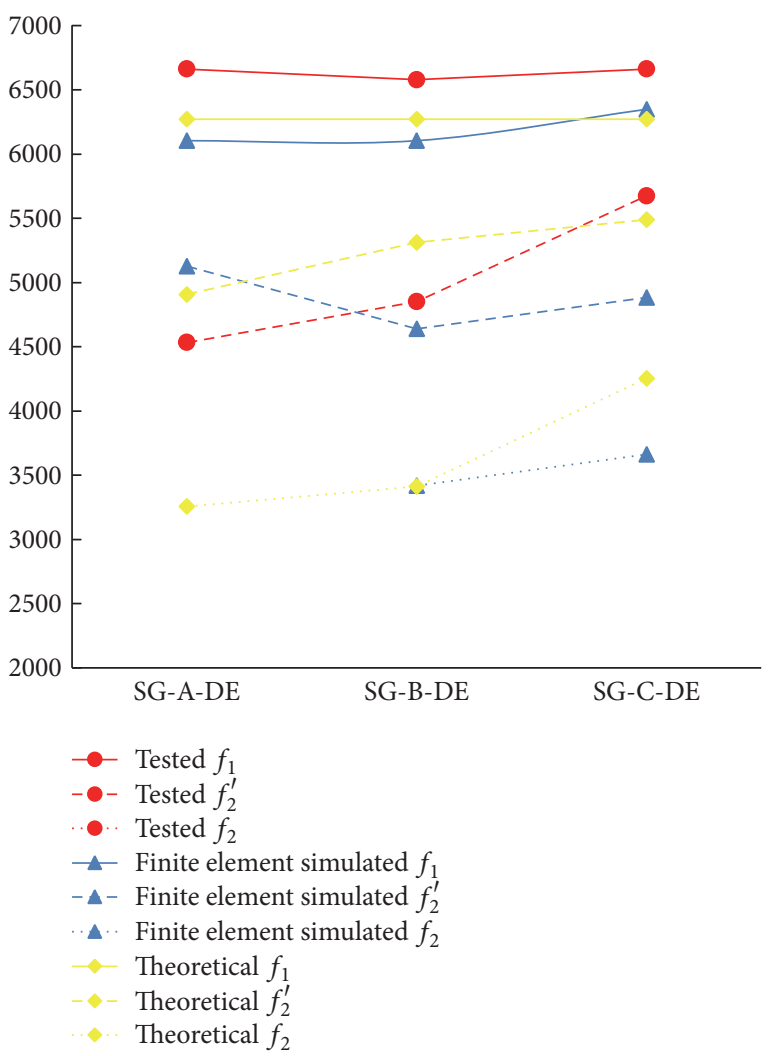

FIGURE 13: Comparison of theoretical values, test values, and finite element simulation values of peak frequency of samples (with defect).

Fundamental Research Funds for the Central University (Grant no. 2015B21414).

\section{References}

[1] S. I. Ivashov, V. I. Makarenkov, A. V. Masterkov et al., "Concrete floor inspection with help of subsurface radar," in Proceedings of the International Conference on Ground Penetrating Radar, vol. 4084 of Proceedings of SPIE, pp. 552-555, Gold Coast, Australie, May 2000.

[2] F. L. Teixeira, W. C. Chew, M. Straka, M. L. Oristaglio, and T. Wang, "Finite-difference time-domain simulation of ground penetrating radar on dispersive, inhomogeneous, and conductive soils," IEEE Transactions on Geoscience and Remote Sensing, vol. 36, no. 6, pp. 1928-1937, 1998. 
[3] N. J. Carino, “The impact-echo method: an overview," American Society of Civil Engineers, no. 69, pp. 785-792, 2001.

[4] D. S. Kim, W. S. Seo, and K. M. Lee, "IE-SASW method for nondestructive evaluation of concrete structure," NDT and E International, vol. 39, no. 2, pp. 143-154, 2006.

[5] M. T. A. Chaudhary, "Effectiveness of Impact Echo testing in detecting flaws in prestressed concrete slabs," Construction and Building Materials, vol. 47, pp. 753-759, 2013.

[6] W. Brameshuber and M. Willmes, "Quality control of concrete tunnel shells using impact echo methods," Insight, vol. 39, no. 7, pp. 479-481, 1997.

[7] C. S. Zhou, P. Wang, Z. P. Hu, and H. Zhu, "Numerical simulation of impact-echo method identify the depth of honeycomb damage in unballasted track," Applied Mechanics and Materials, vol. 584-586, pp. 2060-2067, 2014.

[8] M. T. Ghomi, J. Mahmoudi, and M. Darabi, "Concrete plate thickness measurement using the indirect impact-echo method," Nondestructive Testing and Evaluation, vol. 28, no. 2, pp. 119-144, 2013.

[9] R. Medina and M. Garrido, "Improving impact-echo method by using cross-spectral density," Journal of Sound and Vibration, vol. 304, no. 3-5, pp. 769-778, 2007.

[10] M. Ohtsu and T. Watanabe, "Stack imaging of spectral amplitudes based on impact-echo for flaw detection," NDT and E International, vol. 35, no. 3, pp. 189-196, 2002.

[11] C. Colla, "Improving the accuracy of impact-echo in testing post-tensioning ducts," Review of Quantitative Nodestructive Evaluation, vol. 22, pp. 1185-1192, 2003.

[12] A. Sadri, "Application of impact-echo technique in diagnoses and repair of stone masonry structures," NDT and E International, vol. 36, no. 4, pp. 195-202, 2003.

[13] W. J. Zhang, J. H. Wang, and M. M. Jin, "Numerical analysis of DRC segment under inner water pressure based on full-scale test verification for shield tunnel," Tunnelling and Underground Space Technology, vol. 56, pp. 157-167, 2016.

[14] A. Gudmarsson, N. Ryden, H. Di Benedetto, and C. Sauzéat, "Complex modulus and complex Poisson's ratio from cyclic and dynamic modal testing of asphalt concrete," Construction and Building Materials, vol. 88, pp. 20-31, 2015.

[15] M. Sansalone, J.-M. Lin, and W. B. Streett, "A procedure for determining $\mathrm{P}$-wave speed in concrete for use in impact-echo testing using a P-wave speed measurement technique," $A C I$ Materials Journal, vol. 94, no. 6, pp. 531-539, 1997.

[16] K.-I. Song and G.-C. Cho, "Bonding state evaluation of tunnel shotcrete applied onto hard rocks using the impact-echo method," NDT and E International, vol. 42, no. 6, pp. 487-500, 2009.

[17] D. Pratt and M. Sansalone, "Impact-echo signal interpretation using artificial intelligence," ACI Materials Journal, vol. 89, no. 2, pp. 178-187, 1992.

[18] C. Hsiao, C.-C. Cheng, T. Liou, and Y. Juang, "Detecting flaws in concrete blocks using the impact-echo method," NDT \& $E$ International, vol. 41, no. 2, pp. 98-107, 2008.

[19] C.-Y. Wang, C.-L. Chiu, K.-Y. Tsai, P.-K. Chen, P.-C. Peng, and H.-L. Wang, "Inspecting the current thickness of a refractory wall inside an operational blast furnace using the impact echo method," NDT and E International, vol. 66, pp. 43-51, 2014.

[20] M. A. Khaleel, Z. Lin, P. Singh, W. Surdoval, and D. Collin, "A finite element analysis modeling tool for solid oxide fuel cell development: coupled electrochemistry, thermal and flow

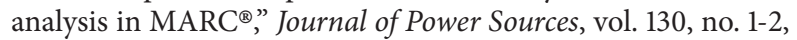
pp. 136-148, 2004.
[21] K.-I. Song and G.-C. Cho, "Numerical study on the evaluation of tunnel shotcrete using the Impact-Echo method coupled with Fourier transform and short-time Fourier transform," International Journal of Rock Mechanics and Mining Sciences, vol. 47, no. 8, pp. 1274-1288, 2010. 


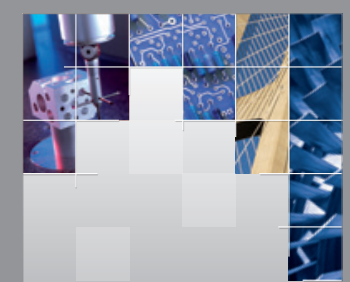

\section{Enfincering}
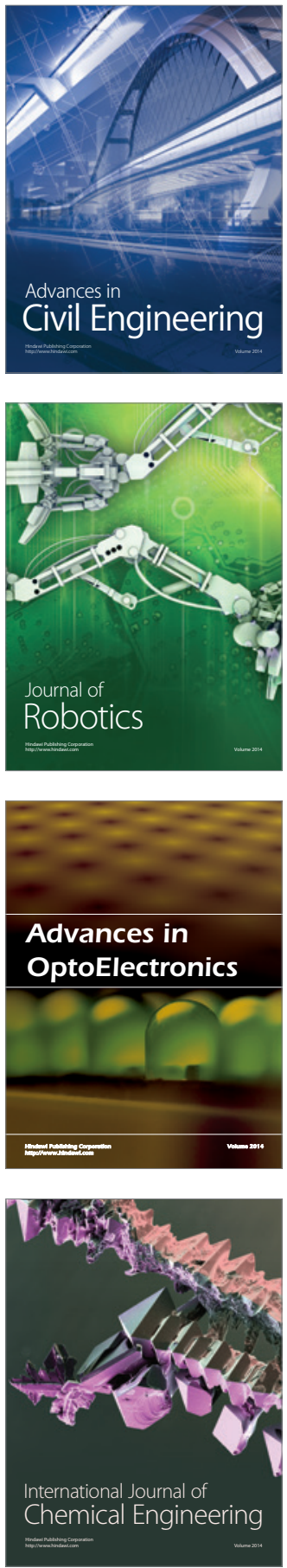

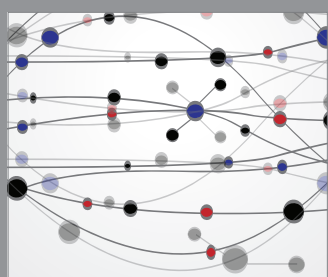

The Scientific World Journal

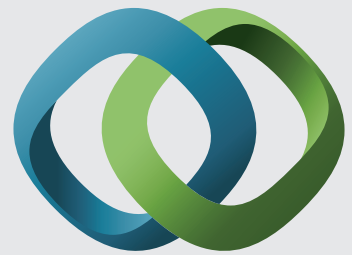

\section{Hindawi}

Submit your manuscripts at

http://www.hindawi.com
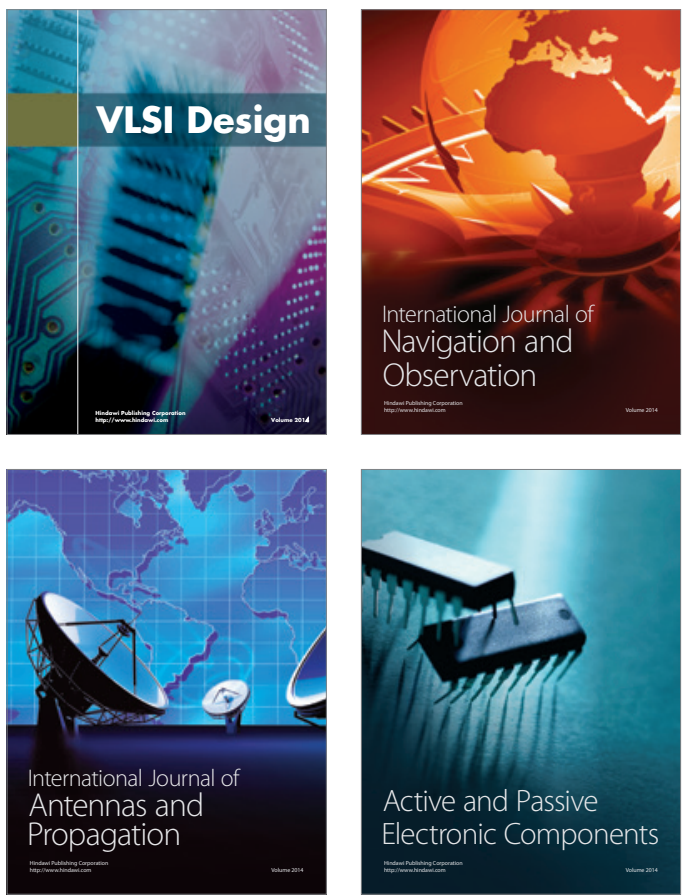
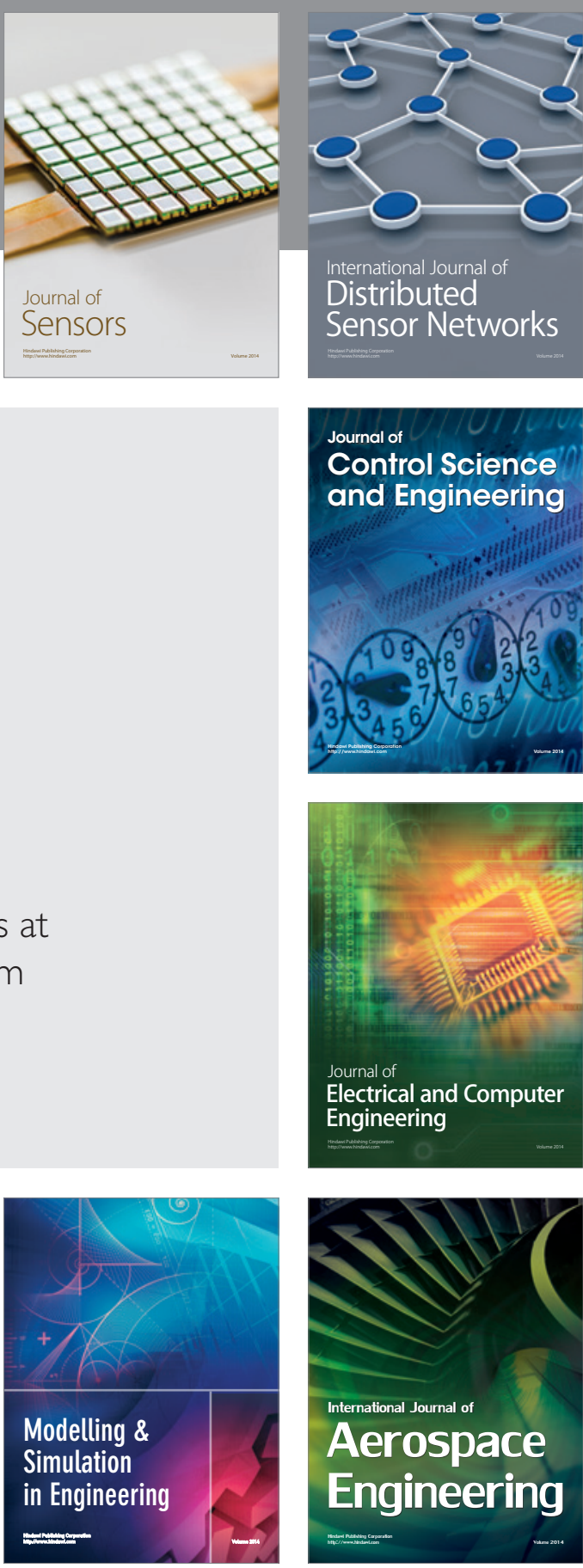

International Journal of

Distributed

Sensor Networks

Journal of

Control Science

and Engineering
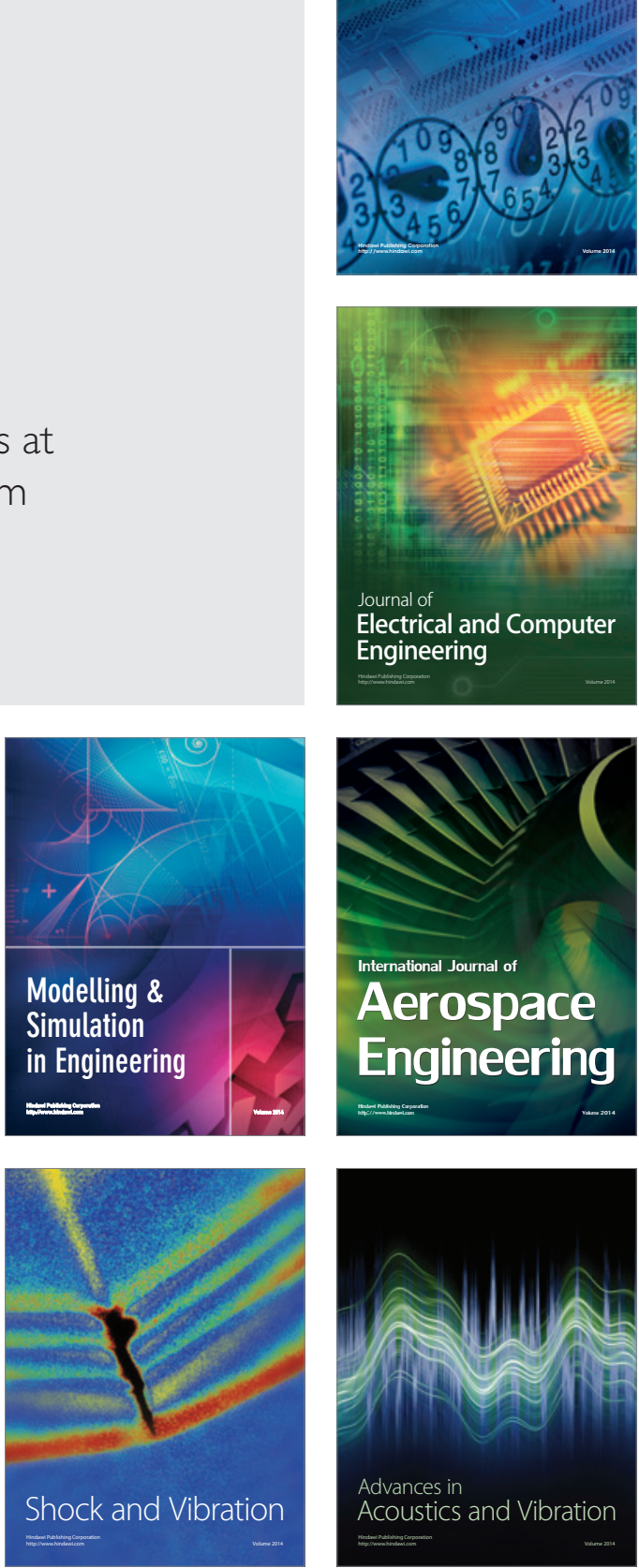